\title{
Ability, Demographic and Personality Predictors of Work Success
}

\author{
Adrian Furnham (1) \\ Norwegian Business School, Oslo, Norway \\ Email: adrian@adrianfurnham.com
}

How to cite this paper: Furnham, A. (2020). Ability, Demographic and Personality Predictors of Work Success. Psychology, 11, 980-991.

https://doi.org/10.4236/psych.2020.116063

Received: June 1, 2020

Accepted: June 27, 2020

Published: June 30, 2020

Copyright $\odot 2020$ by author(s) and Scientific Research Publishing Inc. This work is licensed under the Creative Commons Attribution International License (CC BY 4.0).

http://creativecommons.org/licenses/by/4.0/

\begin{abstract}
794 working people aged around 30 years completed three intelligence (Ravens Progressive matrices: GMA Numerical and GMA Verbal) and one personality test $(16 \mathrm{PF})$ before entering jobs in public service. They were all graduates and there were various sex differences on all measures. They were rated by supervisors each year after they joined the organisation and data were kept on their promotions. Correlations between individual difference factors and the rated criterion scores showed many significant patterns. A series of multiple regressions entered demographic factors (sex, age, social class), arts vs science background, impression management, intelligence test scores, and the personality variables. A mean rating score as well as three years supervisor ratings and number of promotions acted as the criterion scale. Whilst there were some differences between the different criteria, there were some consistent findings. Gender was a consistent predictor whilst there were relatively few personality and ability correlates. Limitations are acknowledged.
\end{abstract}

\section{Keywords}

Intelligence, Personality, Art, Science, Domain-Specificity

\section{Introduction}

To what extent does ability and personality affect work success and promotion? There is a growing interest in personality trait correlates and predictors of individual and organisational performance, satisfaction and derailment (Boudreau \& Boswell, 2001; Furnham, 2018; Judge \& Bono, 2000; Judge, Higgins, Thoresen, \& Barrick, 2006; Kajonius \& Carlander, 2017; Seibert, Crant \& Kraimer, 1999). There have also been meta-analyses on the relationship between personality and leadership (Arvey, Rotundo, Johnson, Zhang, \& McGue, 2006; Judge, Bono, Ilies, 
\& Gerhert, 2002) and personality and job performance (Furnham, 2018; He, Donnellan, \& Mendoza, 2019).

Researchers and reviewers have speculated about which traits (and disorders) are associated with leadership success and failure (Furnham \& Treglown, 2018). Ideally this question is best asked by longitudinal research following individuals with known, psychometrically valid, trait scores as they enter an organisation and then track and trace how they are rated by superior and where and why they got promoted to senior positions or not. This study does just that.

In this study, we examine three correlates of work success measured by supervisor ratings and promotion data: demographics, intelligent and personality. There is a scattered literature on demographic (sex, age, class) correlates of work success measured by a range of outcome variables like supervisor ratings, salary and promotion (Furnham, 2018).

\subsection{Demographics}

This study examines the role of age, sex and parental class on work outcomes. In this sample there were relatively few age differences and around $2 / 3$ of the sample were male. There is a growing debate on sex differences in abilities as well as discrimination against women in certain sectors. This study examines sex differences in all variables and the extent to which they relate to ratings and promotion at work.

\subsection{Intelligence}

In a number of longitudinal studies using large samples Furnham \& Cheng (2013, 2017a, 2017b) found consistently that intelligence played an important role in occupational success measured by many factors, particularly salary. Their data showed a clear process: intelligence predicted educational outcomes which in turn related to occupational prestige and success. However, there have been fewer studies looking at the role of intelligence for those who are partly selected on their educational outcomes. That is, what role does intelligence play in elite samples where there is restriction of range. This study looks at the relationship between intelligence, measured by three established tests when participants had just left school, and later ratings of work success.

\subsection{Personality}

This study also looks at which personality factors predict supervisor ratings and promotions over a three-year period. Personality differences are assessed using the 16PF which is one of the most established and psychometrically robust measures in psychology (Aluja \& Blanch, 2004; Hofer, Horn, \& Eber, 1997; Matthews, 1989; Peng, Khaw, \& Edariah, 1995; Teodorescu, Furnham, \& Macrae, 2017). For instance, Herman \& Usita (1994) found the 16PF could correctly classify $80 \%$ of young appropriate volunteers. It is also been used to predict students who fail at university (Sanchez, Rejano, \& Rodriguez, 2001). The 16PF scales have also been shown to relate logically to ability tests (Gadzella \& Penland, 1995). This study 
examines which of the $16 \mathrm{PF}$ traits consistently relates to success at work

\subsection{Measuring Success}

Most researchers would prefer objective measures of success supplied by an organisation from their files as this hopefully eliminates some of the biases. Many studies in this area have used a mix of measures. Thus Sutin, Costa, Miech, \& Eaton (2009) used occupational prestige (job title), annual income and self-reported job satisfaction. Some studies using both objective (salary) and subjective (career satisfaction) found they had different antecedents (Hirschi \& Jaensch, 2015). Inevitably it is desirable to have a number of reliable measures of success which could be combined into subscale scores or an overall measure.

In this study we had two measures: promotability and manager ratings. Different factors predict upward mobility with specific job types and functions. For instance, using years to promotion as manager and senior manager as a criterion; Furnham, Crump, \& Ritchie (2013) showed shorter times to promotion and success were associated with low Neuroticism, Extraversion, High Conscientiousness, and high Intelligence, as well as being high on the Hogan Dark Side measures of Bold, Mischievous, Imaginative and Colorful, but low on Cautious, Reserved, Diligent and Leisurely. Regarding the three higher order clusters of HDS, "Moving against" was positively associated with speed of promotion, whereas "Moving away from" and "Moving toward" were negatively associated. Speed of promotion is a simple measure of success which has been little used in this literature.

Perhaps the most available performance data on individuals are manager ratings as many organizations have a performance management system which requires them to make annual and perhaps more frequent ratings. Whilst there are well known problems with these assessments, they represent an important source of data for researchers (Furnham, 2019).

\section{Method}

\subsection{Participants}

There were 794 participants of which 543 were male. Their mean age was 29.74 years $(\mathrm{SD}=2.67)$. Nearly all $(92 \%)$ were graduates and just over three-quarters (77.1\%) had studied in the science pre-university stream as opposed to the arts stream. In all 426 males and 155 females had science degrees, and 92 males and 81 females arts degrees. As an index of social class they were asked to rate their household monthly income on a 9 point scale from under $\$ 500$ to over $\$ 10,000$. The mean score was between $\$ 5000$ and $\$ 7499$ which would indicate middle class status.

\subsection{Measures}

1) Ravens Progressive Matrices (Raven, 1965)

This is a very well established "find the odd-man-out" test of logical reason- 
ing. Participants are shown a block $(3 \times 3)$ of patterns with the final one missing. They are presented with 8 alternatives to find the "correct" one by working out the relationship between the patterns. It is one of the most enduring and well researched measures of fluid intelligence (Kline, 1995).

2) The Graduate Management Assessment (GMA-A).

The GMA-A is a high-level test of abstract reasoning ability. It measures the ability to think conceptually to discover underlying pattern within a set of information and to switch easily between contexts and levels of analysis. This test composed of two parts: Verbal and Numerical. Each part takes $30 \mathrm{~min}$ to complete.

a) The Verbal test presents candidates with a short piece of factual prose together with four statements. Respondents have to decide whether the statements are true, false or cannot tell, from the information provided. The participants are encouraged to detach themselves from their own beliefs and prejudices when answering the questions.

b) The Numerical test presents the subjects with a short scenario, followed by three questions. Respondents must choose a right answer from a set of 16 possible responses. It aims at testing the problem-solving skills of the participants.

The local student norms are Numeric (Mean 20.87, SD $=4.54$ ) and Verbal (Mean 35.51, $\mathrm{SD}=4.88$ ).

3) Sixteen Personality Factor (16PF; 5th Edition, Cattell, Cattell \& Cattell, 1990)

This is an established 40-year old, 185 multiple choice item test that measures 16 dimensions of personality. Those scores can be combined into five global factors following the recommended method (Djapo, Kolenovic-Djapo, Dojkic, \& Fako, 2011). The test has been used extensively over the years and is one of the most psychometrically validated of all personality tests (Kline, 1995). The test also has an Impression Management scale which detects those prone to putting themselves in a positive light.

4) Performance Ratings

Once they joined the organisation participants were evaluated by their supervisors on an 8-point scale. This is based on a robust and multi-dimensional performance management system. Candidates were assessed every year on the same system. A mean score for their years' service was also calculated. Over time some were promoted, and this too was logged.

\subsection{Procedure}

All participants were tested as part of a government backed scholarship scheme, before they entered university. All were volunteers and tested under examination conditions. After completing their university studies mainly in the United Kingdom and the United States, they joined government service. Their personal data was kept and recorded and put in their file along with their performance data. The author was given an anonymised data file and permitted to analyse the 
data. Ethics permission was sought and granted.

\section{Results}

1) Sex Differences in Personality and Intelligence.

One way ANOVAs were calculated on all 16 personality traits and the three ability tests. Seven of the sixteen traits showed a significant sex difference. Overall, females were more Factor A. (Warmth) $(F(1,792)=17.45, p<.001)$, I. (Sensitivity) $(F(1,792)=101.98 p<.001)$, and Q2. (Perfectionistic) $(F(1,792)=$ $4.58, p<.05)$, but less good at Factor B (Reasoning) $(F(1,792)=14.19, p$ $<.001)$, less Factor L (Vigilance) $(F(1,792)=7.34, p<.01)$, M. (Abstractness) $(F$ $(1,792)=6.33, p<.01)$, and $\mathrm{N}$ (Privateness) $(F(1,792)=6.70, p<.001)$.

When the five higher factors were calculated (Extraversion, Anxiety, Self Control, Independence, and Tough-mindedness) there were significant differences on two: females had a higher Extraversion score $(F(1,792)=9.96, p$ $<.01)$, and a lower Tough Mindedness score $(F(1,792)=70.14, p<.001)$.

All three ability tests showed significant difference with males scoring higher on two: Ravens $(F(1,792)=7.72, p<.01)$, and Numerical $(F(1,792)=$ $54.05, p<.001)$, but lower on Verbal, which was not significant. Cohen's $d$ showed the biggest effect for Factor I (.93) and for the numerical reasoniong test (.56).

2) Correlations between criteria (ratings, promotions) and predictors (demographics, art-science, ability, personality) were calculated (see Table 1). Notably in Table 1 is the weak correlations between the ratings in years 1 through 3 . Indeed, only the correlation beteen years 1 and 2 were significant. There are a number of possible explanations for this finding: first that participants performance changed from year to year; secondly that as the job changed and became more complex some performed better and other worse; third that raters were unreliable in their judgements. It is also interesting to note that the correlation between the mean of the ratings and the number of promotions was small ( $r$ $=.14$ ) but significant.

The correlations with the mean ranking showed some interesting results. First, females were ranked higher than males. Next, those who had come from the science stream at university had done better than those in the arts. Third the higher the social class of the participant, as measured by his/her parents monthly income, the more positively predicted ratings.

None of the intelligence test scores correlated with rated performance at work. However four of the 16PF factors were significant. They indicated that the more emotionally stable, dominant (assertive), rule conscious (persistent, conscientious), and socially bold (venturesome, unihibited) the person was, the higher rated they were by their boss. With the exception of gender, none of the significant correlations exceeded $r=.20$. The correlations for year 1 were similar to those with the mean rating except that the art-science stream and the 16PF rule conciousness factor were not significant. However, it did indicate that those par- 
ticiants who were low on vigilance (i.e. trusting) tended to get lower ratings. The ratings from year two showed a similar pattern with the following exceptions: younger people tended to be rated higher; emotional stability seemed less important as a marker of success; the more lively (happy-go-lucky) the person the less well they were evaluated, but the more open to change they were the better they did. The results of the ratings in the third year showed fewer and somewhat different correlations: they indicated younger females with lower reasoning but higher apprehension scores got best rated.

Table 1. Correlation between ratings, promotions, demographics, ability and personality.

\begin{tabular}{|c|c|c|c|c|c|c|c|}
\hline & $\mathrm{X}$ & $\mathrm{SD}$ & Mean & Year 1 PG & Year 2 PG & Year 3 PG & No. of Promotions \\
\hline Year 1 PG & 5.33 & 1.55 & $.729^{\star *}$ & & $.253^{\star *}$ & .035 & .081 \\
\hline Year 2 PG & 5.60 & 1.58 & $.701^{\star *}$ & $.253^{\star *}$ & & .072 & $.120^{*}$ \\
\hline Year 3 PG & 5.45 & 1.67 & $.600^{* *}$ & .035 & .072 & & .078 \\
\hline No. of Promotions & 1.75 & .87 & $.141^{* *}$ & .081 & $.120^{*}$ & .078 & \\
\hline Gender & 1.32 & .47 & $.309^{* *}$ & $.134^{\star *}$ & $.202^{\star *}$ & $.378^{\star *}$ & -.081 \\
\hline Age & 29.74 & 2.67 & -.092 & .030 & $-.122^{*}$ & $-.177^{\star \star}$ & $.315^{\star \star}$ \\
\hline Monthly Household Income & 7.48 & 2.17 & $.177^{\star *}$ & $.122^{*}$ & $.202^{\star *}$ & .075 & .010 \\
\hline Arts/Science Stream & 1.23 & .42 & $.152^{* *}$ & .100 & $.168^{\star *}$ & .060 & -.045 \\
\hline Impression Management & 11.63 & 4.88 & .016 & .072 & -.012 & -.066 & $.100^{*}$ \\
\hline Ravens PMatrices z-score & .06 & .86 & .016 & .082 & .005 & -.071 & -.016 \\
\hline GMANumerical z-score & .22 & .95 & .007 & .086 & .009 & -.103 & $-.115^{\star *}$ \\
\hline GMAVerbal z-score & .31 & .92 & .094 & .060 & .059 & .101 & -.037 \\
\hline Warmth & 14.81 & 4.60 & .030 & .016 & .056 & -.015 & .001 \\
\hline Reasoning & 13.63 & 1.17 & -.028 & .053 & -.016 & $-.184^{\star *}$ & $.110^{*}$ \\
\hline Emotional Stability & 15.01 & 4.46 & $.122^{* *}$ & $.134^{\star *}$ & .092 & -.073 & $.165^{\star *}$ \\
\hline Dominance & 14.09 & 3.98 & $.168^{\star *}$ & $.106^{*}$ & $.145^{\star \star}$ & .092 & .067 \\
\hline Liveliness & 11.78 & 4.85 & -.064 & -.011 & $-.119^{*}$ & -.051 & -.027 \\
\hline Rule-Consciousness & 12.60 & 3.40 & $.126^{*}$ & .045 & .069 & .056 & .047 \\
\hline Sensitivity & 12.60 & 5.08 & .049 & -.014 & .085 & .044 & -.053 \\
\hline Vigilance & 10.67 & 3.77 & -.059 & $-.127^{\star}$ & -.073 & .114 & -.104 \\
\hline Abstractedness & 8.76 & 5.42 & -.055 & -.088 & .085 & -.014 & -.056 \\
\hline Privateness & 11.36 & 4.87 & .024 & .016 & .005 & .026 & -.021 \\
\hline Apprehension & 11.27 & 5.30 & -.005 & -.092 & .013 & $.151^{\star}$ & $-.117^{\star *}$ \\
\hline Openness to Change & 21.67 & 4.73 & .056 & .054 & $.118^{\star}$ & .007 & .060 \\
\hline Self-Reliance & 6.28 & 4.55 & -.063 & -.056 & .042 & .004 & -.021 \\
\hline Perfectionism & 12.04 & 4.83 & .099 & .052 & .061 & .100 & .044 \\
\hline Tension & 8.98 & 5.07 & .012 & -.062 & .026 & .085 & -.042 \\
\hline
\end{tabular}

${ }^{* *} p<.01{ }^{*} p<.05$. 
The correlations for number of promitions over 5 years indicated some very interesting findings. Older people experienced more promotions, which is what we may expect. Those with higher reasoning and emotional stability, but lower apprehension scores, tended to be promoted more often. Interestingly, the impression management scores also predicted promotions.

3) Next regressions were performed to see the relative power of the predictor variables. Five step wise regressions were run using the same criterion variables as shown in Table 2. The predictor variables were entered in five steps: first demography (sex, age, class), then art-science stream, then impression management, thereafter cognitive ability (the three test scores) and finally the 16 personality variables. Table 2 shows the final step in the regression. The first regression showed that $16 \%$ of the total variance could be accounted for by just four scores: Females, from the science stream at university who scored low on trait liveliness (ie were sober and serious) and low on sensitivity (ie were tough minded and self reliant) were most highly rated. The regression for the first year at work accounted for just $5 \%$ of the variance. Brigher females from the university science stream were highest rated. The regression for the second year indicated that seven variables were significant, and that $16 \%$ of the variance could be accounted for. Brighter (Scoring high on Ravens Progressive Matrices) females, from more higher social class backgrounds, who were less prone to impression management and low on Liveliness and vigilance but high on social boldness, got higher ratings.

Women from higher social class backgrounds who scored higher on Ravens Progressive Matrices and social boldness, but lower on vigilance, liveliness and impression management received higher ratings.

Year three showed that although many of the variables nearly reached significance there was only one statistically significant predictor which showed that females were rated higher than males (See Table 3 and Table 4).

Another analysis was performed this time using the five higher order traits rather than the 16 traits. The more reliable totaled mean score indicated that females, form higher social status homes who were higher on traits Independent and Self Control with higher Impression Management were more likely to be promoted.

The same regression was performed on the promotion ratings. The most consistent finding was the older males were more likely to be promoted.

\section{Discussion}

This study examined three types of variables as they predicted work success in highly talented and selected civil servants. Using correlational and regressional analysis it was apparent that gender, and some personality traits were associated with ratings of performance and promotions though intelligence played less part.

We examined three demographic variables in this study. Age was almost always not significant in the ratings because of the restricted range of the sample. 
However, age at entering the organization was related to promotions which is a consistent finding. Older people tended to have more experience and educational qualifications which were rewarded with promotions.

Social class (monthly family income) was related to performance but not promotion ratings. As is often the case, people from higher social class backgrounds did better, no doubt because of various opportunities that they were afforded which could affect their confidence and world view.

Table 2. Regression results with ratings as the criterion scores.

\begin{tabular}{|c|c|c|c|c|c|c|c|c|c|c|}
\hline & \multicolumn{2}{|c|}{ Mean Score } & \multicolumn{2}{|c|}{ Year 1} & \multicolumn{2}{|c|}{ Year 2} & \multicolumn{2}{|c|}{ Year 3} & \multicolumn{2}{|c|}{ Promotions } \\
\hline & Beta & $\mathrm{t}$ & Beta & $\mathrm{t}$ & Beta & $\mathrm{t}$ & Beta & $\mathrm{t}$ & Beta & $\mathrm{t}$ \\
\hline Gender & .374 & $5.944^{* *}$ & .236 & $3.516^{* *}$ & .233 & $3.403^{* *}$ & .390 & $4.947^{* * *}$ & -.034 & -.603 \\
\hline Age & .023 & .384 & .105 & 1.640 & -.076 & -1.198 & -.064 & -.893 & .270 & $5.075^{*}$ \\
\hline $\begin{array}{l}\text { Monthly Household } \\
\text { Income }\end{array}$ & .149 & .267 & .103 & 1.748 & .149 & $2.511^{* *}$ & .051 & .755 & .071 & 1.445 \\
\hline Arts/Science Stream & .137 & $2.260^{*}$ & .141 & $2.188^{*}$ & .092 & 1.375 & .018 & .253 & -.019 & -.358 \\
\hline $\begin{array}{l}\text { Impression } \\
\text { Management }\end{array}$ & -.121 & -1.535 & -.060 & -.714 & -.234 & $-2.755^{* *}$ & .082 & .866 & .035 & .502 \\
\hline RPM z-score & .104 & 1.810 & .070 & 1.142 & .122 & $1.982^{*}$ & .022 & .312 & -.050 & -.945 \\
\hline GMAN z-score & .081 & 1.138 & .169 & $2.557^{\star *}$ & .062 & .935 & -.037 & -.490 & -.142 & $-2.493^{*}$ \\
\hline GMAV z-score & .045 & .762 & .018 & .283 & -.016 & -.253 & .130 & 1.866 & .050 & .952 \\
\hline Warmth & -.040 & -.527 & -.033 & -.407 & .112 & 1.419 & -.118 & -1.360 & .038 & .573 \\
\hline Reasoning & .004 & .061 & .037 & .607 & .032 & .522 & .113 & -1.625 & .053 & 1.034 \\
\hline Emotional Stability & .094 & 1.228 & .033 & .409 & .106 & 1.298 & -.048 & -.521 & .059 & .859 \\
\hline Dominance & .066 & .942 & -.011 & -.153 & .060 & .803 & .060 & .719 & .069 & 1.085 \\
\hline Liveliness & -.131 & $-1.951^{*}$ & -.026 & -.363 & -.271 & $-3.815^{\star *}$ & -.026 & -.329 & -.1049 & -.793 \\
\hline Rule-Consciousness & .078 & 1.292 & .023 & .353 & .046 & .708 & .001 & .019 & .007 & .123 \\
\hline Social Boldness & .105 & 1.344 & .101 & 1.207 & .194 & $2.283^{*}$ & -.060 & -.627 & -.070 & -.977 \\
\hline Sensitivity & -.146 & $-2.166^{*}$ & -.136 & -1.887 & -.100 & -1.376 & -.134 & -1.649 & -.076 & -1.270 \\
\hline Vigilance & -.048 & -.787 & -.082 & -1.261 & -.148 & $-2.232^{*}$ & .111 & 1.510 & -.029 & -.549 \\
\hline Abstractedness & -.031 & -.427 & -.024 & -.308 & .071 & .923 & -.099 & -1.146 & .104 & 1.630 \\
\hline Privateness & .019 & .275 & .059 & .810 & .034 & .482 & -.031 & -.387 & -.007 & -.110 \\
\hline Apprehension & .051 & .717 & .020 & .268 & .031 & .398 & .076 & .878 & -.042 & -.650 \\
\hline Openness to Change & .034 & .521 & .023 & .328 & .098 & 1.401 & .061 & .803 & -.077 & -1.272 \\
\hline Self-Reliance & -.027 & -.380 & .027 & .360 & .116 & 1.608 & -.084 & -1.006 & -.030 & -.456 \\
\hline Perfectionism & .049 & .787 & .046 & .698 & .035 & .525 & .045 & .604 & .049 & .890 \\
\hline Tension & .005 & .077 & -.061 & -.858 & .010 & .139 & .037 & .445 & .069 & 1.136 \\
\hline
\end{tabular}

${ }^{* *} p<.01{ }^{\star} p<.05$ Mean Score: $\mathrm{F}(24,291)=3.51, p<.001$ Adj $\mathbf{R}^{2}=.16$; Year 1: $\mathrm{F}(24,291)=1.68, p<.05$ Adj $\mathbf{R}^{2}=.05 \mathrm{Year} 2: \mathrm{F}(24,291)=3.27, p<.001$ Adj $\mathbf{R}^{2}=.16$; Year 3: F $(24,291)=2.88, p<.001$ Adj $\mathbf{R}^{2}=.17$; Promotions: $\mathrm{F}(24,291)=2.43, p<.001$ Adj $\mathbf{R}^{2}=.07$. 
Table 3. Regressions with ratings as criteria and demographics, intelligence and personality as predictors.

\begin{tabular}{|c|c|c|c|c|c|c|c|c|}
\hline & \multicolumn{2}{|c|}{ Mean Score } & \multicolumn{2}{|c|}{ Year 1} & \multicolumn{2}{|c|}{ Year 2} & \multicolumn{2}{|c|}{ Year 3} \\
\hline & Beta & $\mathrm{t}$ & Beta & $\mathbf{t}$ & Beta & $\mathbf{t}$ & Beta & $\mathrm{t}$ \\
\hline Gender & .35 & $5.76^{* *}$ & .17 & $2.67^{*}$ & .24 & $3.52^{* *}$ & .42 & $5.52^{* *}$ \\
\hline Age of entry to workforce & -.03 & -.52 & -.06 & -1.04 & .05 & .78 & -.00 & -.05 \\
\hline Monthly Household Income & .15 & $2.78^{*}$ & .10 & 1.70 & .16 & $2.63^{*}$ & .06 & .84 \\
\hline Arts/Science Stream & -.12 & -1.44 & -.05 & -.65 & -.14 & -1.75 & .01 & .15 \\
\hline Impression Management & .14 & $2.29^{*}$ & .13 & $2.05^{*}$ & .09 & 1.35 & -.00 & -.06 \\
\hline RPM z-score & .09 & 1.59 & .07 & 1.16 & .12 & 1.98 & .02 & .22 \\
\hline GMAN z-score & .08 & 1.32 & .16 & $2.53^{*}$ & .05 & .76 & -.05 & -.70 \\
\hline GMAV z-score & .03 & .45 & -.02 & -3.1 & -.01 & -.21 & .10 & 1.45 \\
\hline Extraversion & -.05 & -.81 & -.05 & -.71 & -.13 & $-1.92^{*}$ & -.03 & -.36 \\
\hline Anxiety & -.09 & -1.24 & -1.5 & -1.82 & -.13 & -1.56 & .15 & 1.63 \\
\hline Self-Control & .16 & $2.42^{*}$ & .07 & .94 & .12 & 1.63 & .08 & 1.00 \\
\hline Independence & .18 & $2.65^{\star}$ & .07 & .98 & .18 & $2.46^{*}$ & .14 & 1.73 \\
\hline Tough Minded & .13 & 1.84 & .10 & 1.24 & -.06 & -.75 & .18 & $2.13^{*}$ \\
\hline$F=$ & \multicolumn{2}{|c|}{5.86} & \multicolumn{2}{|c|}{2.44} & \multicolumn{2}{|c|}{3.63} & \multicolumn{2}{|c|}{4.47} \\
\hline Adj $R^{2}$ & \multicolumn{2}{|c|}{.17} & \multicolumn{2}{|c|}{.06} & \multicolumn{2}{|c|}{.11} & \multicolumn{2}{|c|}{.17} \\
\hline
\end{tabular}

${ }^{* *} p<.01{ }^{*} p<.05$.

Table 4. Regressions with criteria of promotion and predictors of demographics, intelligence and personality.

\begin{tabular}{|c|c|c|c|c|c|c|c|c|}
\hline & \multicolumn{2}{|c|}{ Total Proms } & \multicolumn{2}{|c|}{ Prom 5 yr } & \multicolumn{2}{|c|}{ Prom 4 yr } & \multicolumn{2}{|c|}{ Prom 3 yr } \\
\hline & Beta & $\mathbf{t}$ & Beta & $\mathbf{t}$ & Beta & $\mathbf{t}$ & Beta & $\mathbf{t}$ \\
\hline Age of entry to workforce & .35 & $6.72^{* *}$ & -.08 & -1.15 & .33 & $4.44^{* *}$ & .49 & $12.66^{* *}$ \\
\hline Monthly Household Income & .07 & 1.34 & .05 & 0.69 & .02 & 0.35 & -.02 & -0.63 \\
\hline Arts/Science Stream & .02 & 0.22 & .07 & 0.72 & .00 & 0.06 & -.02 & -0.47 \\
\hline Impression Management & -.05 & -0.91 & -.14 & -1.80 & -.09 & -1.50 & .00 & 0.02 \\
\hline RPM z-score & -.07 & -1.23 & -.10 & -1.21 & -.06 & -1.05 & -.06 & -1.56 \\
\hline GMAN z-score & -.11 & $-1.92^{\star}$ & -.14 & -1.78 & -.10 & -1.54 & .03 & 0.74 \\
\hline Extraversion & -.02 & -0.29 & -.01 & -1.5 & -.01 & -0.22 & .07 & 1.58 \\
\hline Anxiety & -.01 & -0.15 & .06 & 0.62 & .04 & 0.60 & -.06 & -1.30 \\
\hline Self-Control & .02 & 0.30 & .07 & 0.82 & -.04 & -0.58 & -.04 & 0.88 \\
\hline Independence & .07 & 1.09 & .04 & 0.46 & .09 & 1.30 & .01 & 0.28 \\
\hline Tough Minded & .07 & 1.06 & -.10 & -1.06 & .02 & 0.22 & .10 & $2.26^{*}$ \\
\hline $\mathrm{F}=$ & \multicolumn{2}{|c|}{4.96} & \multicolumn{2}{|c|}{2.66} & \multicolumn{2}{|c|}{7.95} & \multicolumn{2}{|c|}{42.70} \\
\hline $\operatorname{Adj} R^{2}$ & \multicolumn{2}{|c|}{.11} & \multicolumn{2}{|c|}{.09} & \multicolumn{2}{|c|}{.24} & \multicolumn{2}{|c|}{.62} \\
\hline
\end{tabular}

${ }^{* *} p<.01{ }^{*} p<.05$. 
However, what was most clear and consistent in these results was the gender of the candidates. Further, there was an interesting connundrum over these findings. It was clear that females were consistently more highly rated than males. There can be a number of possible explanations for this: simply the ratings were accurate and that females outperformed males. It could be that their higher warmth, sensitivity and perfectionism led them to have better performance or a better relationship with their rater (boss). Equally, it could be an organisational attempt to correct for past biases. It would have been interesting to know whether the sex of the rater and the sex of the worker intereacted. Indeed, there is evidence that in many situations female raters are particularly hard on female employees whereas men show less evidence of this (Furnham \& Stringfield, 2001). Yet despite being better rated females were less likely to be promoted. This is an interesting and important finding which left the organsation puzzled and determined to try to find an explanation for this finding, which is yet to be resolved.

There was some evidence that those with an Arts/Social science degree were more highly rated than those with a Science-based degree. It is not clear why this should be the case, except this could be moderated by personality. Indeed, Furnham \& Crump (2013) showed that trait differences showed that arts students scored higher on less desirable traits (i.e. Neuroticism) but lower on more desirable traits (Conscientiousness).

There was little evidence that intelligence played a large part in ratings and promotions though there was some evidence that higher numerical intelligence test scores were related to ratings in the first year, but negatively associated with promotions. This is a surprising finding as many studies have shown the predictive power of intelligence at work (Furnham, 2018). However, there may be a relatively simple explanation for these results: restrictions of range as intelligence test scores were used as a robust "cut-off" to enter the civil service. Indeed, most candidates were around 1.5 standard deviations above the norm.

The personality results at facet and domain level were interesting. The correlational results suggested that emotional stability and dominance were related to high ratings while the regressional results suggested that those low on sensitivity and liveliness were ratest highest. The regression with the higher order factors indicated two of the five related to ratings, namely Self-Control, which is related to Concientiousness, and Independent which is related to Openness. This confirms the results of many other studies on personality correlates of work success (Furnham, 2018).

Overall the results suggested that demographic, ability, and personality factors were more closely related to performance ratings than promotion. In many organisations it seems promotion is more a function of length of service than anything else and this may be particularly the case in the public sector. However, we only had three years of data and it would be most desirable to have both rating and promotion data over a longer span.

This study had good "real-world" data with a large population. However the results may well have been influenced by the rigorous selection criteria (particularly 
intelligence) and the lack of easily measure outcome variables that could be rated.

\section{Conflicts of Interest}

The author declares no conflicts of interest regarding the publication of this paper.

\section{References}

Aluja, A., \& Blanch, A. (2004). Replicability of First-Order 16PF-S Factors. Personality and Individual Differences, 37, 667-677. https://doi.org/10.1016/j.paid.2003.10.001

Arvey, R. D., Rotundo, M., Johnson, W., Zhang, Z., \& McGue, M. (2006). The Determinants of Leadership Role Occupancy: Genetic and Personality Factors. The Leadership Quarterly, 17, 1-20. https://doi.org/10.1016/j.leaqua.2005.10.009

Boudreau, J., \& Boswell, W. (2001). Effects of Personality on Executive Career Success in the United States and Europe. Journal of Vocational Behaviour, 58, 53-81.

https://doi.org/10.1006/jvbe.2000.1755

Djapo, N., Kolvenovic-Djapo, J., Djokic, R., \& Fako, I. (2011). Relationship between Cattell's 16PF and Fluid and Crystallised Intelligence. Personality and Individual Differences, 51, 63-67. https://doi.org/10.1016/j.paid.2011.03.014

Furnham, A. (2018). Personality and Occupational Success. In V. Zeigler-Hill, \& T. K. Shackelford (Eds.), The SAGE Handbook of Personality and Individual Differences (pp. 537-551). New York: Sage. https://doi.org/10.4135/9781526451248.n23

Furnham, A. (2019). Rater Congruence in 360 Feedback: Explaining Why Ratings of the Same Person Differ and What Organisations Should Do about It. In D. Bracken, A. Church, J. Fleenor, \& D. Rose (Eds.), Handbook of Strategic 360 Degree Feedback (pp. 391-408). Oxford: Oxford University Press. https://doi.org/10.1093/oso/9780190879860.003.0016

Furnham, A., \& Cheng, H. (2013). Factors Influencing Adult Earnings: Findings from a Nationally Representative Sample. Journal of Socio-Economics, 44, 120-125. https://doi.org/10.1016/j.socec.2013.02.008

Furnham, A., \& Cheng, H. (2017a). Childhood Cognitive Ability Predicts Adult Financial Well-Being. Journal of Intelligence, 5, 3. https://doi.org/10.3390/jintelligence5010003

Furnham, A., \& Cheng, H. (2017b). Socio-Demographic Indicators, Intelligence, and Locus of Control as Predictors of Adult Financial Well-Being. Journal of Intelligence, 5, 11. https://doi.org/10.3390/jintelligence5020011

Furnham, A., \& Crump, J. (2013) The Sensitive, İmaginative, Articulate Art Student and Conservative, Cool, Numerate Science Student: Individual Differences in Art and Sciences Students. Learning and Individual Differences, 25, 150-155. https://doi.org/10.1016/j.lindif.2013.03.002

Furnham, A., \& Stringfield, P. (2001). Gender Difference in Rating Reports: Female Managers Are Harsher Raters, Particularly of Males. Journal of Managerial Psychology, 16, 281 289. https://doi.org/10.1108/02683940110392020

Furnham, A., \& Treglown, L. (2018). High Potential Personality and Intelligence. Personality and Individual Differences, 128, 81-87. https://doi.org/10.1016/j.paid.2018.02.025

Furnham, A., Crump, J., \& Ritchie, W. (2013). What It Takes: Ability, Demographic, Bright and Dark Side Trait Correlates of Years to Promotion. Personality and Individual Differences, 55, 952-956. https://doi.org/10.1016/j.paid.2013.07.469

Gadzella, B. M., \& Penland, E. (1995). Is Creativity Related to Scores on Critical Think- 
ing? Psychological Reports, 77, 817-818. https://doi.org/10.2466/pr0.1995.77.3.817

He, Y., Donnellan, M., \& Mendoza, A. (2019). Five-Factor Personality Domains and Job Performance. Journal of Research in Personality, 82, Article ID: 103848. https://doi.org/10.1016/j.jrp.2019.103848

Herman, K., \& Usita, P. (1994). Predictive Validity of the 16PF in Screening Volunteers for Big Brothers/Big Sisters. Psychological Reports, 74, 249-250. https://doi.org/10.2466/pr0.1994.74.1.249

Hirschi, A., \& Jaensch, V. K. (2015). Narcissism and Career Success: Occupational SelfEfficacy and Career Engagement as Mediators. Personality and Individual Differences, 77, 205-208. https://doi.org/10.1016/j.paid.2015.01.002

Hofer, S., Horn, J., \& Eber, H. (1997). A Robust Five-Factor Structure of the 16PF: Strong Evidence from Independent Rotation and Confirmatory Factorial Invariance Procedures. Personality and Individual Differences, 23, 247-269. https://doi.org/10.1016/S0191-8869(97)00025-1

Judge, T. A., \& Bono, J. E. (2000). Five-Factor Model of Personality and Transformational Leadership. Journal of Applied Psychology, 85, 751. https://doi.org/10.1037/0021-9010.85.5.751

Judge, T. A., Bono, J. E., Ilies, R., \& Gerhardt, M. W. (2002). Personality and Leadership: A Qualitative and Quantitative Review. Journal of Applied Psychology, 87, 765. https://doi.org/10.1037/0021-9010.87.4.765

Judge, T. A., Higgins, C. A., Thoresen, C. J., \& Barrick, M. R. (2006). The Big Five Personality Traits, General Mental Ability, and Career Success across the Life Span. Personnel Psychology, 52, 621-652. https://doi.org/10.1111/j.1744-6570.1999.tb00174.x

Kajonius, P., \& Carlander, A. (2017). Who Gets Ahead in Life? Personality Traits and Childhood Background in Economic Success. Journal of Economic Psychology, 59, 164-179. https://doi.org/10.1016/j.joep.2017.03.004

Kline, P. (1995). Handbook of Psychological Testing. London: Routledge.

Matthews, G. (1989). The Factor Structure of the 16PF: Twelve Primary and Three Secondary Factors. Personality and Individual Differences, 10, 931-940. https://doi.org/10.1016/0191-8869(89)90057-3

Peng, R., Khaw, H., \& Edariah, A. (1995). Personality and Performance of Premedical Medical Students. Medical Education, 29, 283-288. https://doi.org/10.1111/j.1365-2923.1995.tb02850.x

Sanchez, M., Rejano, E., \& Rodriguez, Y. (2001). Personality and Academic Productivity in the University Student. Social Behaviour and Personality, 29, 299-305. https://doi.org/10.2224/sbp.2001.29.3.299

Seibert, S., Crant, J., \& Kraimer, M. (1999). Proactive Personality and Career Success. Journal of Applied Psychology, 84, 416-427. https://doi.org/10.1037/0021-9010.84.3.416

Sutin, A. R., Costa Jr., P. T., Miech, R., \& Eaton, W. W. (2009). Personality and Career Success: Concurrent and Longitudinal Relations. European Journal of Personality, 23, 71-84. https://doi.org/10.1002/per.704

Teodorescu, A., Furnham, A., \& Macrae, I. (2017). Trait Correlates of Success at Work. International Journal of Selection and Assessment, 25, 36-42. https://doi.org/10.1111/ijsa.12158 